J. Indones. Math. Soc.

Vol. 17, No. 2 (2011), pp. 73-83.

\title{
ON SET-INDEXED RESIDUAL PARTIAL SUM LIMIT PROCESS OF SPATIAL LINEAR REGRESSION MODELS
}

\author{
WAYAN SOMAYASA \\ Department of Mathematics, Universitas Haluoleo \\ Jl. H.E.A. Mokodompit, Kendari 93232, Indonesia \\ wayan.somayasa@yahoo.de
}

\begin{abstract}
In this paper we derive the limit process of the sequence of set-indexed least-squares residual partial sum processes of observations obtained form a spatial linear regression model. For the proof of the result we apply the uniform central limit theorem of Alexander and Pyke (1986) and generalize the geometrical approach of Bischoff (2002) and Bischoff and Somayasa (2009). It is shown that the limit process is a projection of the set-indexed Brownian sheet onto the reproducing kernel Hilbert space of this process. For that we define the projection via Choquet integral of the regression function with respect to the set-indexed Brownian sheet.

Key words: Set-indexed Brownian sheet, set-indexed partial sum process, spatial linear regression model, least-squares residual, Choquet integral.
\end{abstract}

2000 Mathematics Subject Classification: $62 \mathrm{G}, 62 \mathrm{H}, 62 \mathrm{~J}$.

Received: 07-04-2011, revised: 18-07-2011, accepted: 09-08-2011. 